\title{
Medical Termination of Delayed Miscarriage: Four-Year Experience with an Outpatient Protocol
}

\section{Terminação médica de gravidez inviável do $1^{\circ}$ trimestre: quatro anos de experiência com um protocolo de tratamento em ambulatório}

\author{
Joana Lyra ${ }^{1}$ João Cavaco-Gomes ${ }^{1}$ Marina Moucho ${ }^{1}$ Nuno Montenegro ${ }^{1,2,3}$ \\ ${ }^{1}$ Department of Gynecology and Obstetrics, Centro Hospitalar de São \\ João, Porto, Portugal \\ 2 Faculdade de Medicina, Universidade do Porto, Porto, Portugal \\ ${ }^{3}$ Instituto de Saúde Pública da Universidade do Porto, Porto, Portugal \\ Address for correspondence Joana Lyra, MSc, Departmento de \\ Ginecologia e Obstetrícia, Centro Hospitalar de São João, Porto, \\ Alameda Prof. Hernâni Monteiro, 4200-319 Porto, Portugal \\ (e-mail: joanaritalyra@gmail.com).
}

Rev Bras Ginecol Obstet 2017;39:529-533.

\begin{abstract}
Keywords

- delayed miscarriage

- vaginal misoprostol

- outpatient management

Purpose To evaluate the efficacy of an outpatient protocol with vaginal misoprostol to treat delayed miscarriage.

Methods Retrospective analysis of prospectively collected data on women medically treated for missed abortion with an outpatient protocol. The inclusion criteria were: ultrasound-based diagnosis of missed abortion with less than 10 weeks; no heavy bleeding, infection, inflammatory bowel disease or misoprostol allergy; no more than 2 previous spontaneous abortions; the preference of the patient regarding the medical management. The protocol consisted of: 1) a single dose of $800 \mathrm{\mu g}$ of misoprostol administered intravaginally at the emergency department, after which the patients were discharged home; 2 ) clinical and ultrasonographic evaluation 48 hours later - if the intrauterine gestational sac was still present, the application of $800 \mu \mathrm{g}$ of vaginal misoprostol was repeated, and the patients were discharged home; 3) clinical and ultrasonography evaluation 7 days after the initiation of the protocol - if the intrauterine gestational sac was still present, surgical management was proposed. The protocol was introduced in January 2012. Every woman received oral analgesia and written general recommendations. We also gave them a paper form to be presented and filled out at each evaluation.

Results Complete miscarriage with misoprostol occurred in 340 women (90.2\%). Surgery was performed in 37 (9.8\%) patients, representing the global failure rate of the protocol. Miscarriage was completed after the first misoprostol administration in 208 (55.2\%) women, with a success rate after the second administration of $78.1 \%$ (132/169). The average age of the women with complete resolution using misoprostol was superior to the average age of those who required surgery (33.99 years versus 31.74 years; $p=0.031$ ). Based on the ultrasonographic findings in the first evaluation, the women diagnosed with fetal loss achieved greater success rates compared with those diagnosed with empty sac $(p=0.049)$.
\end{abstract}

received

January 27, 2017

accepted

June 27, 2017

published online

August 29, 2017
DOI https://doi.org/

10.1055/s-0037-1606242.

ISSN 0100-7203.
Copyright $\odot 2017$ by Thieme Revinter

Publicações Ltda, Rio de Janeiro, Brazil
License terms

(c) (i) $\ominus$ (\$) 


\section{Resumo}

\author{
Palavras-chave \\ - aborto retido \\ - misoprostol vaginal \\ - tratamento em \\ ambulatório
}

Conclusions We conclude this is an effective and safe option in the majority of delayed miscarriage cases during the first trimester, reducing surgical procedures and their consequences.

Objetivo Avaliar a eficácia de um protocolo de tratamento médico da gravidez inviável do primeiro trimestre $\left(\mathrm{Gl} 1^{\circ} \mathrm{T}\right)$ com misoprostol vaginal em regime de ambulatório.

Métodos Análise retrospectiva de dados colhidos prospectivamente de grávidas tratadas com misoprostol vaginal em ambulatório. Os critérios de inclusão foram: diagnóstico de $\mathrm{G} 11^{\circ} \mathrm{T}$ com $<10$ semanas de gestação; ausência de hemorragia abundante, infeção, doença inflamatória intestinal ou alergia ao misoprostol; $\leq 2$ abortamentos anteriores; e preferência da paciente por tratamento médico. $\mathrm{O}$ protocolo consiste em: dia 0 -aplicação de misoprostol intravaginal $(800 \mu \mathrm{g})$ no Serviço de Urgência e alta para o domicílio; dia 2-se persistência de saco gestacional intrauterino, aplicação de segunda dose de misoprostol $(800 \mu \mathrm{g})$ e alta; Dia 7-se persistência de saco gestacional intrauterino, proposto esvaziamento uterino instrumentado. O protocolo foi implementado em janeiro de 2012. Todas as grávidas receberam analgesia oral e informação por escrito com recomendações gerais. Receberam ainda um formulário a ser preenchido em cada vinda à urgência.

Resultados Das 377 mulheres incluídas, observou-se abortamento completo em 340 $(90,2 \%)$. As restantes $37(9,8 \%)$ necessitaram de tratamento cirúrgico - taxa de falência global do protocolo. Em 208 (55,2\%), o sucesso foi observado ao fim da $1^{\text {a }}$ dose, com uma taxa de eficácia da $2^{\text {a }}$ dose de 78,1\% (132/169). A idade média das mulheres com sucesso do tratamento médico foi superior à das mulheres sem sucesso do mesmo (33,99 versus 31,74 anos; $p=0,031)$. O sucesso do tratamento foi maior quando o diagnóstico ecográfico inicial era de um embrião sem vitalidade comparado com os casos de ovo anembrionado ( $p=0.049)$.

Conclusões Conclui-se que esta é uma opção de tratamento eficaz e segura na maioria das situações de $\mathrm{Gl} 1^{\circ} \mathrm{T}$, evitando a necessidade de internamento e de intervenção cirúrgica.

\section{Introduction}

Non-viable first trimester intrauterine pregnancy is the most common complication of early pregnancy. It accounts for $20 \%$ of all pregnancies, ${ }^{1}$ and may present as delayed miscarriage (fetal loss and empty sac), spontaneous or incomplete miscarriage. The approach to early pregnancy failure can be either surgical (dilation and suction curettage), medical (with misoprostol or mifepristone) or expectant.

Traditionally, the surgical treatment was the first option in cases of incomplete and delayed miscarriage. Moreover, we have now evidence that supports more conservative approaches to early pregnancy loss, namely medical treatment and expectant management. ${ }^{2,3}$ In a meta-analysis in which medical treatment was compared with expectant management, the former was 2.77-fold more likely to induce complete evacuation of conception products. ${ }^{4}$

Over the years, many studies observed the efficacy and acceptance of misoprostol as a treatment option for incomplete and delayed miscarriage, ${ }^{3,5,6}$ and as an option in outpatient management protocols, with success rates ranging from $77.3 \%$ to $92.7 \% .^{5,7-9}$
The efficacy of the medical treatment with prostaglandins depends on both the dose and route of administration. Hence, the vaginal administration of misoprostol seems to be more effective than the oral administration, and has less side effects. ${ }^{10}$

The aim of this study was to evaluate the efficacy of an outpatient protocol for the medical management of delayed miscarriage with vaginal misoprostol.

\section{Methods}

\section{Patient Selection and Outpatient Protocol}

We performed a retrospective analysis of the women medically treated with misoprostol for delayed miscarriage (fetal loss and empty sac) in an outpatient protocol. Data was collected prospectively using a paper form that was presented and filled out at each evaluation.

The women enrolled in this study were diagnosed either occasionally on a routine ultrasound scan, or when they were admitted to the emergency department because of early bleeding in pregnancy. The ultrasound findings considered 
necessary for the diagnosis of delayed miscarriage were one of the following: an irregular intrauterine gestational sac with $\geq 25 \mathrm{~mm}$ of diameter and no embryo and/or no yolk sac; an intrauterine gestational sac or an embryo with an abnormal growth upon ultrasound over a minimum of one week; or an intrauterine gestational sac with an embryo with a crownrump length $\geq 7 \mathrm{~mm}$ and no cardiac activity observed.

The inclusion criteria were: ultrasound-based diagnosis of delayed miscarriage with gestational age based on ultrasound fetal measurement $<10$ weeks; no heavy bleeding; no signs of infection; no more than 2 previous spontaneous miscarriages; no history of misoprostol allergy; no history of inflammatory bowel disease; and the preference of the patient regarding the medical management. For patients with delayed miscarriage with $\geq 10$ weeks of gestation or with 2 or more previous spontaneous miscarriage, inpatient management was recommended.

The women meeting these criteria were treated according to the following outpatient protocol: a single dose of $800 \mu \mathrm{g}$ of misoprostol administered intravaginally at the emergency department, after which the patients were discharged home; clinical and ultrasonography evaluation 48 hours later and, if the intrauterine gestational sac was still present, a second dose of $800 \mu \mathrm{g}$ of misoprostol was administered intravaginally, and the patients were discharged home - if no gestational sac was observed, no further evaluation was performed; clinical and ultrasonographic evaluation 7 days after the initiation of the protocol for those who received a second dose of misoprostol - if the intrauterine gestational sac was still present, surgical management was proposed. Oral analgesia was prescribed to every woman, and they received written general recommendations. They were instructed to return if any of the following symptoms occurred: heavy vaginal bleeding, intense vomiting, abdominal cramps, or temperature $>38.5^{\circ} \mathrm{C}$. The patients also received a paper form to be presented and filled out at each evaluation.

If any of the following clinical findings were present, the women were considered not eligible to enroll on the protocol: exuberant vaginal bleeding and/or hemoglobin $<10 \mathrm{mg} / \mathrm{dL}$; signs or symptoms of infection; inflammatory bowel disease; allergy to misoprostol; recurrent miscarriages; and ultrasound suspicion of gestational trophoblastic disease or ectopic pregnancy.

The criterion used to document success after the medical management was the absence of the gestational sac upon transvaginal ultrasound.

Written informed consent was not required because this protocol was introduced in our department as a routine standard practice. The present study was approved by our ethics committee.

\section{Evaluated Outcomes}

The main outcome evaluated was the global success rate of this protocol, represented by women achieving a complete miscarriage with the medical treatment. The success of the protocol was defined by the absence of the gestational sac upon a transvaginal ultrasound evaluation. We also analyzed the success rate achieved with each misoprostol application.

\section{Statistical Analysis}

The statistical significance was determined for the categorical variables with the Chi-squared $\left(x^{2}\right)$ test, and for the continuous variables, we used standard parametric tests; $p<0.05$ considered statistically significant. The Statistical analysis was performed using the Statistical Package for The Social Sciences (IBM SPSS Statistics, IBM Corp., Armonk, NY, US) software, version 21.0.

\section{Results}

A total of 377 women diagnosed with delayed miscarriage met the inclusion criteria and were elected to enroll on this outpatient protocol. The average age of the women enrolled was 33.8 years. We obtained information about parity regarding 321 women: 167 (52\%) were nulliparous, 135 women (42.1\%) were in their first pregnancy, and 32 (10\%) had already had at least 1 previous abortion, spontaneous or not. The remaining 154 (48\%) had had at least one live birth. According to the ultrasonographic criteria, $23.5 \%$ were diagnosed with empty sac, with a mean diameter of $23 \mathrm{~mm}$, and $76.5 \%$ were diagnosed with fetal loss, with a mean crown-rump length (CRL) of $12 \mathrm{~mm}$. The women diagnosed with fetal loss were older ( 34.12 years versus 32.64 years, $p=0.048$ ) than the ones diagnosed with empty sac (-Table $\mathbf{1}$ ).

Complete miscarriage with the medical treatment was observed in 340 (90.2\%) women. Surgical treatment was performed in the remaining 37 women (9.8\%), representing the global failure rate of the medical treatment (-Table 2 ).

The miscarriage was complete after the first administration of misoprostol in 208 (55.2\%) women, with a success rate after the second administration of $78.1 \%(132 / 169)$ ( - Table 2$)$.

The mean age of the women who achieved complete resolution with the medical treatment was superior to the mean age of those who required surgical procedures (33.99 years versus 31.74 years; $p=0.031$ ) ( - Table 3 ). The success of the medical treatment was not different between nulliparous and multiparous women $(p=0.732)$.

According to the ultrasonographic findings in the first evaluation, the women diagnosed with fetal loss achieved greater success rates with the medical treatment when compared with those diagnosed with empty sac $(p=0.049)$ ( - Table 3 ). The mean diameter of the gestational sac and the mean CRL

Table 1 Study population characteristics

\begin{tabular}{|l|l|}
\hline Median age (years) & $\overline{\mathbf{X}}=33.8$ \\
\hline Nulliparous $(n=321)$ & $\mathrm{n}=167(52 \%)$ \\
\hline, 1st pregnancy & $\mathrm{n}=135(42.1 \%)$ \\
\hline,$>1$ abortion & $\mathrm{n}=32(10 \%)$ \\
\hline Parity $\geq 1(n=321)$ & $\mathrm{n}=154(48 \%)$ \\
\hline Empty sac $(n=375)$ & $\mathrm{n}=88(23.5 \%)$ \\
\hline \multicolumn{1}{|c}{ Gestational sac diameter $(\mathrm{mm})$} & $\overline{\mathrm{X}}=23$ \\
\hline Fetal loss $(n=375)$ & $\mathrm{n}=287(76.5 \%)$ \\
\hline , Crown-rump length $(\mathrm{mm})$ & $\overline{\mathbf{X}}=12$ \\
\hline
\end{tabular}


Table 2 Results observed for the treatment of delayed miscarriage with vaginal misoprostol in an outpatient setting

\begin{tabular}{|c|l|l|}
\hline & $\mathbf{n}$ & $\%$ \\
\hline Medical treatment (success) & 340 & 90.2 \\
\hline . After 1st dose of misoprostol & 208 & 55.2 \\
\hline . After 2nd dose of misoprostol & 132 & 35 \\
\hline Surgery (treatment failure) & 37 & 9.8 \\
\hline
\end{tabular}

Table 3 Success and failure rates in treating delayed miscarriage with vaginal misoprostol

\begin{tabular}{|c|c|c|c|}
\hline & Success & Failure & $p^{*}$ \\
\hline Maternal age & $\overline{\mathbf{x}}=33.99$ & $\overline{\mathrm{X}}=31.74$ & 0.031 \\
\hline \multicolumn{4}{|l|}{ Nulliparity } \\
\hline - Nulliparous & $150(89.8 \%)$ & $17(10.2 \%)$ & \multirow[t]{2}{*}{0.732} \\
\hline - Parity $\geq 1$ & $141(91.6 \%)$ & $13(8.4 \%)$ & \\
\hline \multicolumn{4}{|c|}{ Ultrasound findings } \\
\hline - Empty sac & $74(84.1 \%)$ & $14(15.9 \%)$ & \multirow[t]{2}{*}{0.049} \\
\hline - Fetal loss & $264(92 \%)$ & $23(8 \%)$ & \\
\hline $\begin{array}{l}\text { Gestational sac } \\
\text { diameter (mm) }\end{array}$ & $\overline{\mathrm{x}}=23$ & $\overline{\mathrm{X}}=19$ & 0.194 \\
\hline $\begin{array}{l}\text { Crown-rump } \\
\text { length (mm) }\end{array}$ & $\overline{\mathrm{x}}=12$ & $\bar{x}=13$ & 0.733 \\
\hline
\end{tabular}

Note: ${ }^{*} p<0.05$ were considered statistically significant.

were not statistically different between the cases with and without success of the medical treatment $(23 \mathrm{~mm}$ versus $19 \mathrm{~mm}, p=0.194 ; 12 \mathrm{~mm}$ and $13 \mathrm{~mm}, p=0.733$ respectively). This difference was also observed when considering only the first administration of misoprostol $(p=0.014)$, but that was not the case for the second administration of misoprostol.

In terms of complications that may arise from this approach, we could obtain information from 329 cases (87.3\%). There was one case of major vaginal bleeding after the first dose of vaginal misoprostol, which was treated with an emergency surgical management (uterine aspiration), with no need of blood transfusion to stabilize the patient. A case of infection treated with surgery and oral antibiotics was diagnosed one week after initiating the medical treatment during the second routine visit to the emergency department. The evolution of both cases was favorable, with no more complications observed, and a global complication rate of $0.61 \%$.

\section{Discussion}

\section{Main Findings and Interpretation}

In 2005, a study concluded that $400 \mu \mathrm{g}$ of misoprostol selfadministered intravaginally every 4 hours, up to a maximum dose of $1,200 \mu \mathrm{g}$, had a success rate of $91 \%$, and it was a safe treatment option. ${ }^{11}$ In the same year, the efficacy, safety, and acceptability of this treatment were assessed in a large, randomized trial that concluded that treatment with $800 \mu \mathrm{g}$ of vaginal misoprostol is a safe and acceptable approach, with a success rate of $\sim 84 \%{ }^{6}$ Two years later, 75 women were treated for delayed miscarriage with $800 \mu \mathrm{g}$ of vaginal misoprostol plus 2 additional doses of $400 \mu \mathrm{g}$ each to take orally the following day: $77.3 \%$ of them achieved complete medical evacuation with this treatment. ${ }^{7}$ Recently, in April 2017, a comprehensive review and meta-analysis ${ }^{12}$ concluded that the administration of misoprostol is an effective method to solve missed abortion, and both $600 \mu \mathrm{g}$ of sublingual misoprostol or $800 \mu \mathrm{g}$ of vaginal misoprostol may be good choices as a first dose. However, they state that the ideal dose, medication interval, and the safety of waiting at home need further research.

In this study, we present the results of an outpatient protocol for the medical treatment of delayed miscarriage, and we observed success rates comparable to those of the most recent studies on this topic. A 2012 study compared the effectiveness and adverse effects of $800 \mu \mathrm{g}$ and $600 \mu \mathrm{g}$ of vaginal misoprostol every 24 hours for 2 days in an outpatient setting, with the authors concluding that $600 \mu \mathrm{g}$ was as effective as $800 \mu \mathrm{g}$ in inducing complete uterus evacuation after missed abortion (with success rates of $87.8 \%$ and $90.6 \%$ respectively; $p=0.18) .{ }^{5}$ Moreover, this proved to be a safe treatment, with few adverse effects. Our success rate (90.2\%), which includes both women receiving doses of $800 \mu \mathrm{g}$ and $1,600 \mu \mathrm{g}$ (if two doses were needed), is similar to that observed in the literature with the same dose of misoprostol. ${ }^{5}$

Another study reported the prospective outcomes of the medical management of delayed miscarriage in an Australian cohort composed of 264 women. Doses of $400 \mu \mathrm{g}$ or $800 \mu \mathrm{g}$ of misoprostol were administered intravaginally, at presentation, and repeated the following day if the products of conception were still there. With a success rate of $78 \%$, this was considered an effective, safe and acceptable treatment. ${ }^{8}$ The discrepancy observed between theirs and our results may be explained by the success criteria used, as in their study they used an endometrium thickness $>30 \mathrm{~mm}$ as an indication for surgery.

More recently, in 2014, a randomized control trial with 154 women assessed the differences between outpatient and inpatient treatments with vaginal misoprostol. Doses of $800 \mu \mathrm{g}$ of misoprostol were administered vaginally every 8 hours to a maximum of 3 doses. The overall success rate was of $92.7 \%$, and a higher success was observed with the outpatient treatment compared with the inpatient treatment, even though this was not statistically significant. Moreover, the side effects and complications were similar between the two groups. ${ }^{9}$ The higher success rate may be a consequence of the higher dose of misoprostol (a total of 2,400 $\mu \mathrm{g}$ ) administered within a shorter interval.

Our results are consistent with reports from previous studies in terms of effectiveness. The differences observed in the success rate may be, in part, explained by the criteria used to classify the treatment as successful. In our study, we used absence of gestational sac upon transvaginal ultrasound as the criterion to document success after the medical management of delayed miscarriage. This is associated with the highest short- and longterm success rates, and also with mild symptoms following the 
treatment with vaginal misoprostol. ${ }^{13}$ However, other studies used endometrial cavity $<15 \mathrm{~mm}$ thick as the criterion for success. $^{5,7,9,11}$ The occurrence of major side effects was rare $(0.61 \%)$, which is in agreement with previous findings that considered vaginal misoprostol a safe treatment. ${ }^{8,14}$ We did not collect information about the long-term safety of the treatment, but according to a study a recent study, vaginal misoprostol does not impair future fertility. ${ }^{15}$

In this study we achieved a greater success rate with the medical treatment among the women diagnosed with fetal loss when compared with those diagnosed with empty sac. Other researchers have also observed this difference and suggested that it would be reasonable to divide first trimester miscarriages into different groups according to the ultrasonography findings, because they have different success rates. $^{16}$

\section{Strengths and Limitations}

This study assessed the efficacy of vaginal misoprostol for first trimester delayed miscarriage according to the protocol described before. We also searched for adverse effects after the initiation of the medical protocol, with only one case of infection and one of vaginal bleeding leading to surgical treatment. Our findings are concordant with previous studies that concluded for the safety of this drug when administered vaginally, with only minor adverse effects (diarrhea, nausea, fever and crampy abdominal pain), none of them life-threatening. In the randomized control trial by Zhang et $\mathrm{al}^{6}$, nausea was observed in $53 \%$ of the sample, vomiting in $20 \%$, diarrhea in $24 \%$, and abdominal pain in $99 \%$, with hemorrhage and pelvic infection being rare ( $1 \%$ or less). We did not have any case of gastrointestinal side effects, and this may be due to the prophylactic prescription of antiemetic drugs and painkillers.

\section{Conclusion}

In summary, our study shows that vaginal misoprostol for the outpatient medical management of delayed miscarriage is an effective and safe option in the majority of the cases, reducing the number of women subjected to surgical procedures and the consequences of such an approach. Moreover, it combines the advantages of being performed in an outpatient setting (with lesser costs and more comfort for the patients), with the reassurance that the misoprostol administration is performed by doctors, not depending on the patients' skills, and enabling an evaluation between the administration of the doses of misoprostol.

\section{References}

1 National Institute for Health and Clinical Excellence. Ectopic pregnancy and miscarriage: diagnosis and initial management. Clinical guideline. Manchester: NICE; 2012

2 Coughlin LB, Roberts D, Haddad NG, Long A. Medical management of first trimester miscarriage (blighted ovum and missed abortion): is it effective? J Obstet Gynaecol 2004;24(01):69-71

3 Ayres-de-Campos D, Teixeira-da-Silva J, Campos I, Patrício B. Vaginal misoprostol in the management of first-trimester missed abortions. Int J Gynaecol Obstet 2000;71(01):53-57

4 Sotiriadis A, Makrydimas G, Papatheodorou S, Ioannidis JP. Expectant, medical, or surgical management of first-trimester miscarriage: a meta-analysis. Obstet Gynecol 2005;105(5 Pt 1):1104-1113

5 Barceló F, De Paco C, López-Espín JJ, Silva Y, Abad L, Parrilla JJ. The management of missed miscarriage in an outpatient setting: 800 versus $600 \mu \mathrm{g}$ of vaginal misoprostol. Aust N Z J Obstet Gynaecol 2012;52(01):39-43

6 Zhang J, Gilles JM, Barnhart K, Creinin MD, Westhoff C, Frederick MM; National Institute of Child Health Human Development (NICHD) Management of Early Pregnancy Failure Trial. A comparison of medical management with misoprostol and surgical management for early pregnancy failure. N Engl J Med 2005;353(08):761-769

7 Shankar M, Economides DL, Sabin CA, Tan B, Kadir RA. Outpatient medical management of missed miscarriage using misoprostol. J Obstet Gynaecol 2007;27(03):283-286

8 Petersen SG, Perkins AR, Gibbons KS, Bertolone JI, Mahomed K. The medical management of missed miscarriage: outcomes from a prospective, single-centre, Australian cohort. Med J Aust 2013; 199(05):341-346

9 Ng BK, Annamalai R, Lim PS, Aqmar Suraya S, Nur Azurah AG, Muhammad Abdul Jamil MY. Outpatient versus inpatient intravaginal misoprostol for the treatment of first trimester incomplete miscarriage: a randomised controlled trial. Arch Gynecol Obstet 2015;291(01):105-113

10 Kulier R, Kapp N, Gülmezoglu AM, Hofmeyr GJ, Cheng L, Campana A. Medical methods for first trimester abortion. Cochrane Database Syst Rev 2011;(11):CD002855

11 Sifakis S, Angelakis E, Vardaki E, Fragouli Y, Koumantakis E. Highdose misoprostol used in outpatient management of first trimester spontaneous abortion. Arch Gynecol Obstet 2005;272(03):183-186

12 Wu HL, Marwah S, Wang P, Wang QM, Chen XW. Misoprostol for medical treatment of missed abortion: a systematic review and network meta-analysis. Sci Rep 2017;7(01):1664

13 Reynolds A, Ayres-de-Campos D, Costa MA, Montenegro N. How should success be defined when attempting medical resolution of first-trimester missed abortion? Eur J Obstet Gynecol Reprod Biol 2005;118(01):71-76

14 Black KI, de Vries BS, Moses F, Pelosi M, Cong A, Ludlow J. The impact of introducing medical management on conservative and surgical management for early pregnancy miscarriage. Aust N Z J Obstet Gynaecol 2017;57(01):93-98

15 Bord I, Gdalevich M, Nahum R, Meltcer S, Anteby EY, Orvieto R. Misoprostol treatment for early pregnancy failure does not impair future fertility. Gynecol Endocrinol 2014;30(04):316-319

16 Vejborg TS, Nilas L, Rørbye C. Medical management of first trimester miscarriage according to ultrasonographic findings. Acta Obstet Gynecol Scand 2007;86(05):604-609 